\title{
Tale of a hairy tail: Rapunzel Syndrome
}

\author{
Vishal Sharma ${ }^{1} \cdot$ Hema Gupta $^{2} \cdot$ Sandeep Lamoria $^{1} \cdot$ Arka De $^{1}$
}

Received: 21 September 2015/ Accepted: 5 October 2015/Published online: 23 October 2015 (c) SIMI 2015

A 12 year old girl presented with recurrent episodes of vomiting containing ingested food as well as with occasional episodes of hematemesis. The child had been symptomatic for the prior 2 months. She had a failure to gain weight and height. On examination the child appeared malnourished, was underweight, had pallor, and her hair was thin and sparse. Her haemoglobin was $7.8 \mathrm{~g} / \mathrm{dL}$, peripheral smear showed microcytes and hypochromic red cells. An iron profile confirmed iron deficiency anaemia. Abdominal roentgenogram (Fig. 1) revealed a mottled appearance in the region of the stomach, which stretched the fundic air shadow. Gastroduodenoscopy was performed with the finding of a hairy mass occupying most of the gastric lumen causing a gastric ulcer (Fig. 2). This hairy mass was seen to extend across the pylorus (Fig. 3) into the distal duodenum (Fig. 4). On questioning the parents, they confirmed that the child had a habit of eating her own hair. A diagnosis of Rapunzel syndrome was made. The patient underwent surgical removal of the hair-ball, and was referred to follow-up with psychiatry.

Bezoars are collections of indigestible material that may accumulate in the gastrointetstinal tract (usually stomach), and may result in symptoms like gastric outlet obstruction. When this material is hair, the bezoar is termed a trichobezoar. Rapunzel syndome is a term used to describe a trichobezoar that has reached from the stomach into the small intestine due to a tail like extension of the bezoar [1].

Vishal Sharma

docvishalsharma@gmail.com

1 Department of Gastroenterology, PGIMER and Dr RML Hospital, Delhi 110001, India

2 Department of Paediatrics, PGIMER and Dr RML Hospital, Delhi, India

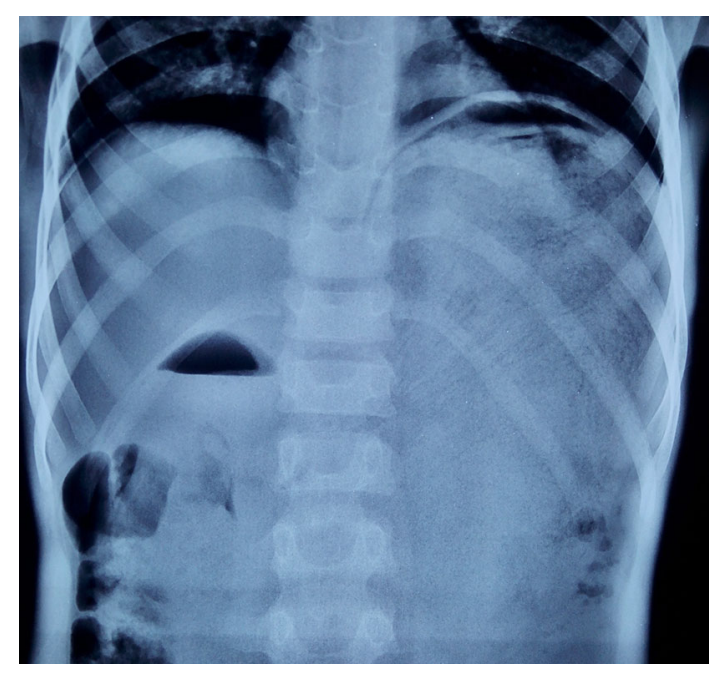

Fig. 1 Abdominal roentgenogram showing stretched fundic air due to a mottled intra-gastric mass

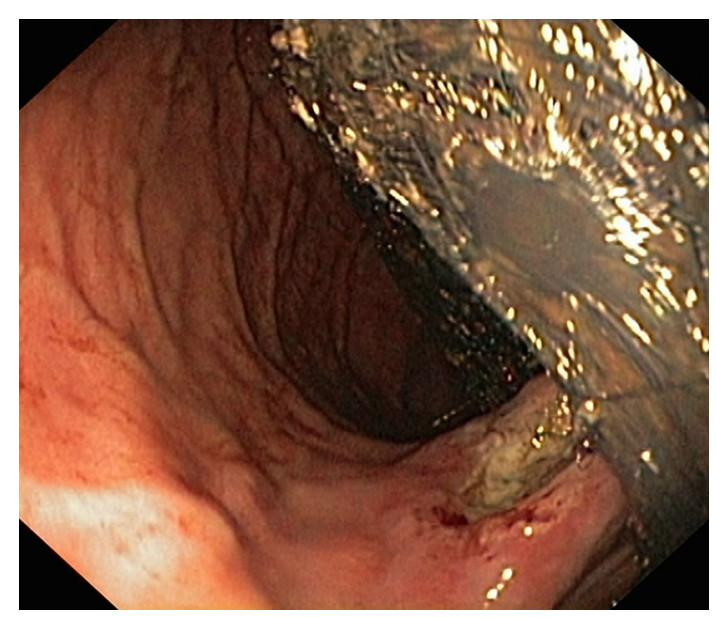

Fig. 2 Endoscopic images of the hair ball in the stomach with a gastric ulcer 


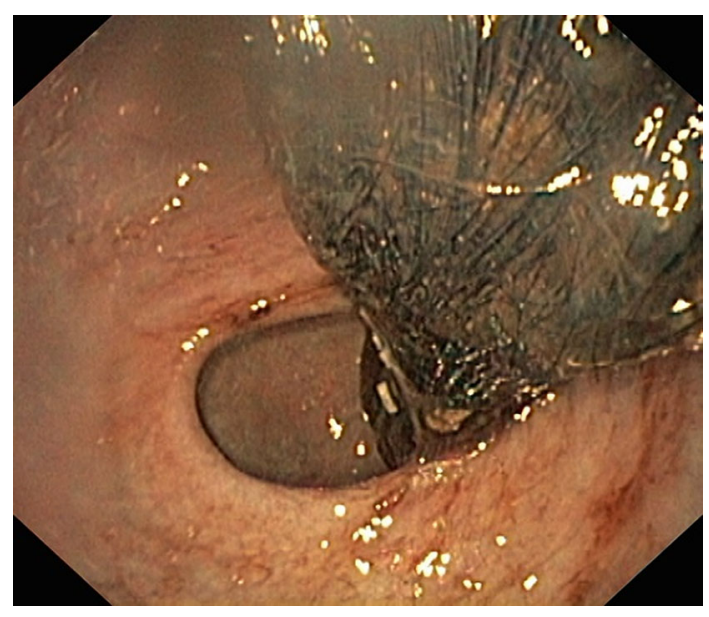

Fig. 3 The hair ball crossing the pylorus

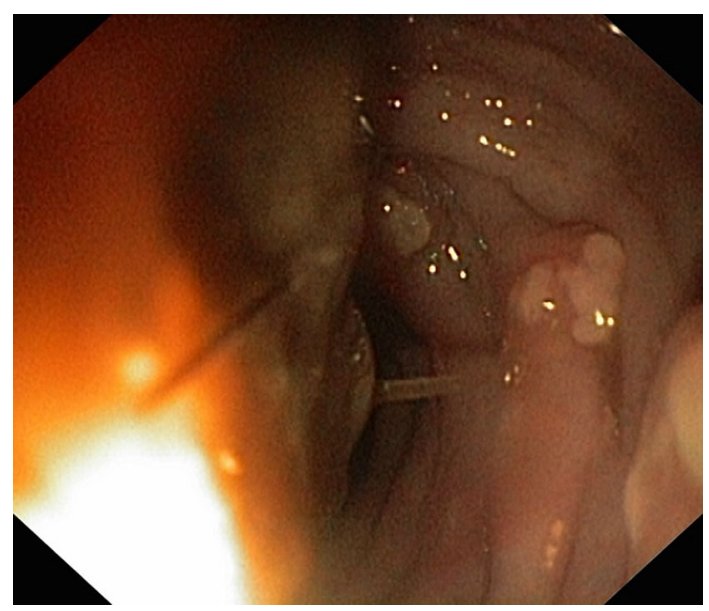

Fig. 4 Hair ball reaching the duodenum

Named after a fairy tale princess with long tresses, the syndrome usually occurs in females with psychiatric conditions [2]. At least two disorders: trichotillomania i.e removing one's own hair and then eating it (trichophagia), contribute to the genesis of this bizarre syndrome [1]. The treatment is incomplete unless the psychiatric condition is managed else the disease will recur necessitating multiple surgeries. The condition occurs because of the failure of gastric peristalsis to remove the hair from the stomach, with its eventual conglomeration resulting in formation of a hairball. The entity remains asymptomatic unless obstruction of either the stomach or the small bowel precipitates symptoms. Other reported manifestations include bleeding, perforation, intussusception, pancreatitis and obstructive jaundice [3]. Although endoscopic removal or dissolution with coca-cola have been described, we did not venture with these modalities due to the presence of a large ulcer possibly due to the pressure necrosis of gastric mucosa [4]. Surgery is the definitive modality but close psychiatric follow-up is recommended to prevent recurrence [5].

\section{Compliance with ethical standards}

Conflict of interest None.

Statement of human and animal rights No animal studies were conducted. We followed Helsinki declaration and its amendments and followed all standard national and international ethical standards.

Informed consent Consent from father of the patient for publication of this report was taken.

\section{References}

1. Gonuguntla V, Joshi DD (2009) Rapunzel syndrome: a comprehensive review of an unusual case of trichobezoar. Clin Med Res 7:99-102

2. Grimm Brothers: Rapunzel. Translated by Godwin-Jones R. Richmond, Virginia Commonwealth University Department of Foreign Languages, 1994-1999

3. Gorter RR, Kneepkens CM, Mattens EC, Aronson DC, Heij HA (2010) Management of trichobezoar: case report and literature review. Pediatr Surg Int 26:457-463

4. Iwamuro M, Okada H, Matsueda $\mathrm{K}$, Inaba $\mathrm{T}$, Kusumoto $\mathrm{C}$, Imagawa A, Yamamoto K (2015) Review of the diagnosis and management of gastrointestinal bezoars. World J Gastrointest Endosc 7:336-345

5. Jiledar Singh G, Mitra SK (1996) Gastric perforation secondary to recurrent trichobezoar. Indian J Pediatr 63:689-691 